GA-A24479

\title{
DISSOLVED OXYGEN REDUCTION IN THE DIII-D NEUTRAL BEAM ION SOURCE COOLING \\ SYSTEM
}

\author{
by \\ H. YIP, J. BUSATH, and S. HARRISON
}




\section{DISCLAIMER}

This report was prepared as an account of work sponsored by an agency of the United States Government. Neither the United States Government nor any agency thereof, nor any of their employees, makes any warranty, express or implied, or assumes any legal liability or responsibility for the accuracy, completeness, or usefulness of any information, apparatus, product, or process disclosed, or represents that its use would not infringe privately owned rights. Reference herein to any specific commercial product, process, or service by trade name, trademark, manufacturer, or otherwise, does not necessarily constitute or imply its endorsement, recommendation, or favoring by the United States Government or any agency thereof. The views and opinions of authors expressed herein do not necessarily state or reflect those of the United States Government or any agency thereof. 


\title{
DISSOLVED OXYGEN REDUCTION IN THE DIII-D NEUTRAL BEAM ION SOURCE COOLING SYSTEM
}

\author{
by \\ H. YIP, J. BUSATH, and S. HARRISON
}

This is a preprint of a paper presented at the 20th IEEE/NPSS Symposium on Fusion Engineering, San Diego, California, October 14-17, 2003 and to be published in Fusion Science and Technology.

\author{
Work supported by \\ the U.S. Department of Energy \\ under Contract No. DE-AC03-99ER54463
}




\title{
Dissolved Oxygen Reduction in the DIII-D Neutral Beam Ion Source Cooling System
}

\author{
H. Yip, J. Busath, and S. Harrison \\ General Atomics, PO Box 85608, San Diego, California 92186-5608
}

\begin{abstract}
Neutral beam ion sources (NBIS) are critical components for the neutral beam injection system supporting the DIII-D tokamak. The NBIS must be cooled with $3028 \mathrm{l} / \mathrm{m}$ $(800 \mathrm{gpm})$ of de-ionized and de-oxygenated water to protect the sources from overheating and failure. These ion sources are currently irreplaceable. Since the water cooled molybdenum components will oxidize in water almost instantaneously in the presence of dissolved oxygen (DO), de-oxygenation is extremely important in the NBIS water system. Under normal beam operation the DO level is kept below 5 ppb. However, during weeknights and weekends when neutral beam is not in operation, the average DO level is maintained below $10 \mathrm{ppb}$ by periodic circulation with a $74.6 \mathrm{~kW}(100 \mathrm{hp})$ pump, which consumes significant power. Experimental data indicated evidence of continuous oxygen diffusion through non-metallic hoses in the proximity of the NBIS. Because of the intermittent flow of the cooling water, the DO concentration at the ion source(s) could be even higher than measured downstream, and hence the concern of significant localized oxidation/corrosion. A new $3.73 \mathrm{~kW}$ ( $5 \mathrm{hp}$ ) auxiliary system, installed in the summer of 2003 , is designed to significantly reduce the peak and the time-average DO levels in the water system and to consume only a fraction of the power.
\end{abstract}

\section{INTRODUCTION}

This paper describes the reduction of dissolved oxygen in the DIII-D neutral beam ion source cooling water system resulting from recent upgrades and the August 2003 installation of a new $3.73 \mathrm{~kW}(5 \mathrm{hp})$ auxiliary circulation pump and associated components.

The DIII-D Tokamak utilizes the neutral beam injection system for plasma heating and current drive (Fig. 1). The neutral beam ion sources (NBIS) are critical components and great care must be taken keep them in peak operating condition. To protect each $5 \mathrm{MW}$ ion source from overheating and sustaining irreparable damage, they must be actively cooled during beam operations. Cooling water is circulated through a series of gun-drilled holes in the copper components and through small molybdenum accelerating grid rail tubes

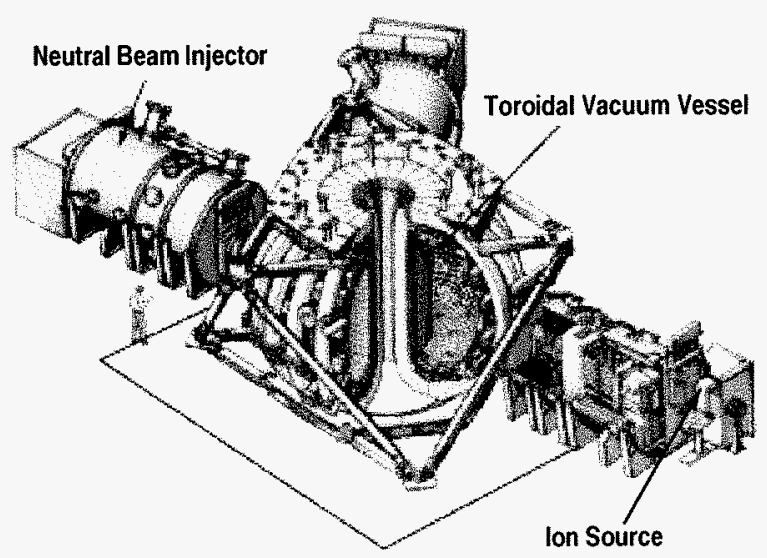

Fig. 1. Cutaway view of DIII-D tokamak and 3 of 4 neutral beam injectors. and grid masking plates that are directly exposed to the arc discharges and high power ion beams. The cooling water is deionized to keep its resistivity greater than $2 \mathrm{M} \Omega-\mathrm{cm}$ for personnel safety and proper high voltage operation of the NBIS, but less than $10 \mathrm{M} \Omega-\mathrm{cm}$ to preclude loss of material in the copper cooling passages. The cooling water must also be de-oxygenated to reduce damage to the molybdenum cooling passages, which readily oxidize in the presence of even small amounts of dissolved oxygen (DO). This oxidation can result in significant loss of material over time as evidenced by a reduction of the molybdenum grid rail tube wall thickness from $635 \mu \mathrm{m}\left(0.025^{\prime \prime}\right)$ to $-320 \mu \mathrm{m}$ (0.0126") (Fig. 2). This leads to decreased strength and integrity of the accelerating grid rails and eventual failure of the currently irreplaceable ion sources. It has been determined that, to avoid such damage, DO levels must be kept below 10 ppb.

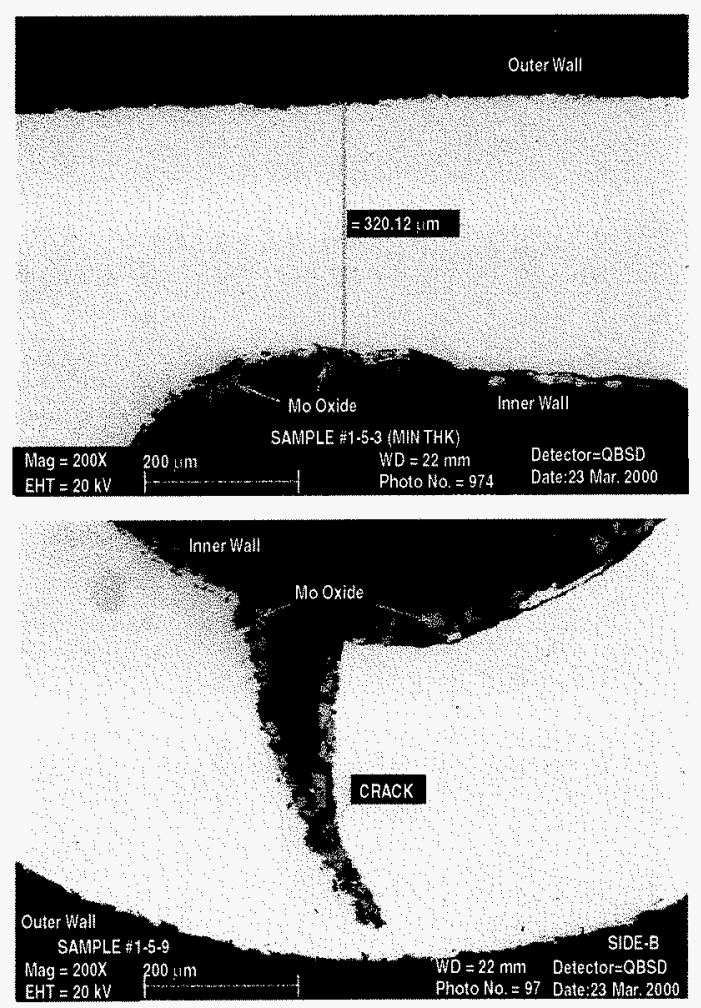

Fig. 2. Cross-sections of a failed molybdenum grid rail tube as seen under an electron microscope.

\section{OPERATIONS AND PERFORMANCE AFTER INITIAL UPGRADE}

A previous upgrade of the NBIS cooling system involved separating it from a shared $113,560 \ell(30,000$ gal $)$ system and adding additional pumps and equipment necessary to convert it to a stand alone $4,542 \ell$ (1200 gal) system. A programmable logic controller (PLC), for control and real-time data acquisition, was integrated with a remote computer interface to 
operate the system as well as monitor and log numerous system parameters (Fig. 3). Recognizing that each ion source is valued at upwards of one million dollars with no spare or new sources available, close monitoring and precise control of these parameters is required to safeguard them from permanent damage and minimize downtime and cost for maintenance and repair.

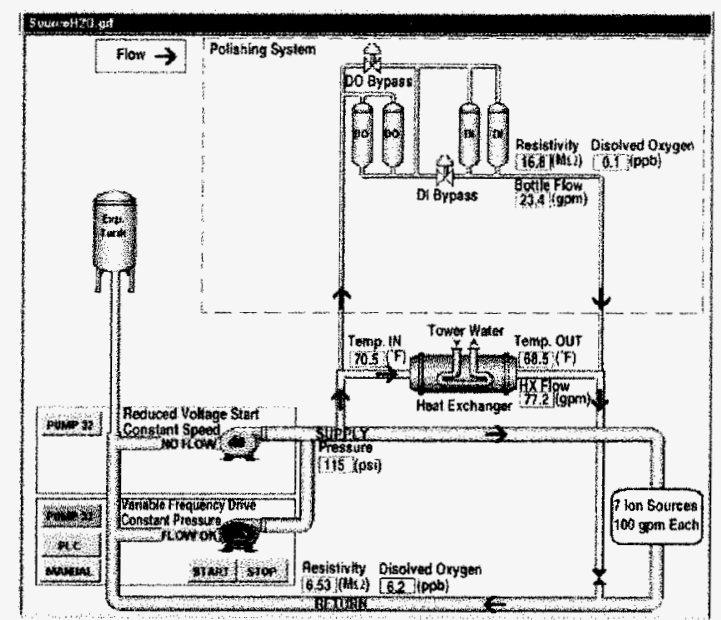

Fig. 3. Remote computer interface screen for NBIS cooling water system.

During normal beam operations a single $74.6 \mathrm{~kW}(100 \mathrm{hp})$ pump runs continuously to provide $3028 \mathrm{\ell} / \mathrm{m}(800 \mathrm{gpm})$ of flow; $379 \ell / \mathrm{m}(100 \mathrm{gpm})$ to cool each of seven ion sources, $303 \mathrm{~L} / \mathrm{m}(80 \mathrm{gpm})$ to a plate type heat exchanger to remove waste heat, and $75 \mathrm{l} / \mathrm{m}(20 \mathrm{gpm})$ to de-ionizing and deoxygenating resin bottles to maintain water quality. The cooling system is maintained at a positive pressure at all times to prevent any air leaks.

Until recently the NBIS cooling system was shut down at night and over the weekend when there were no beam operations and only operated weekly during maintenance periods. Analysis of the newly available historical data files revealed a potentially serious problem with increasing DO levels while the cooling system was shut down. High DO levels, proportional to the elapsed time the cooling system was off, were observed after each startup. To mitigate these high DO levels, a pump was run to provide circulation even when the beams were not operating. Cost of continuous circulation was determined to be prohibitive and since heat rejection was not required, short interval pumping seemed feasible. After several iterations, it was determined that PLC operation of the $100 \mathrm{hp}$ pump on a one hour cycle significantly reduced startup DO levels. Once each hour the PLC would run the pump for ten minutes to adequately mix circulating water, ensuring resistivity and DO measurements are representative of overall system levels. After ten minutes the pump would be shut off when the water quality criteria of resistivity $>2 \mathrm{M} \Omega-\mathrm{cm}$ and DO levels $<4.5 \mathrm{ppb}$ were met. This normally required an additional 10-20 min of operation.

After reducing startup DO levels, startup performance could be viewed with greater resolution and a new problem emerged. Transient DO levels were observed to oscillate wildly with an exponentially decaying envelope, and then clean up to an acceptable level (Fig. 4).

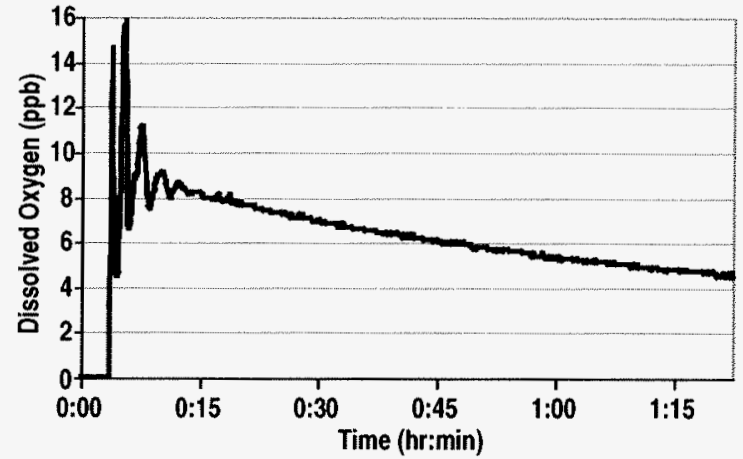

Fig. 4. Oscillating DO levels upon startup.

The longer the system was shut down the higher the amplitude of the DO level oscillations and the longer it took to clean up to acceptable levels The measured period of the oscillation coincided with the loop transport time of the water in the system. The oscillations of measured DO likely result from a large localized influx of oxygen, which upon circulation mixes with the rest of the water and is eventually removed from the system via the de-oxygenating bottles. Investigations of startup behavior with different valve line-ups lead to the conclusion that the large influx of oxygen appears to originate at the numerous non-metallic tubing and hoses that are part of and provide connections to the NBIS (Figs. 5 \& 6).

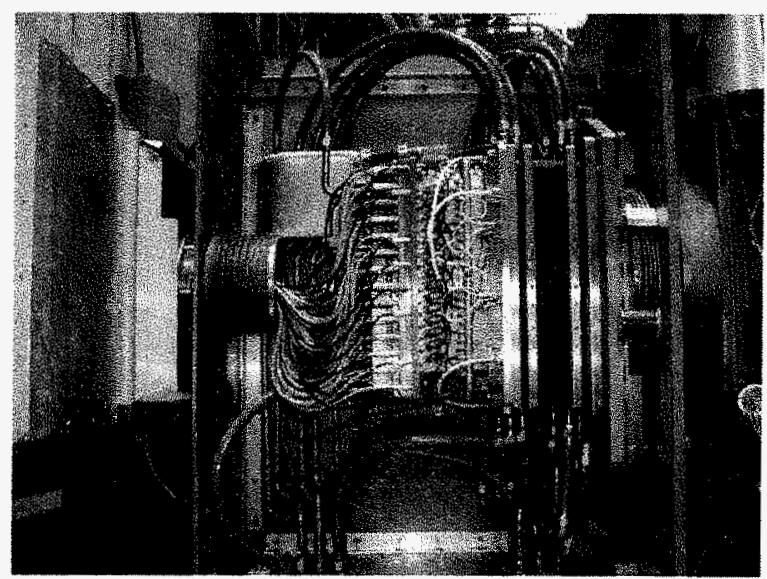

Fig. 5. Ion source mounted on beamline, with covers removed exposing non-metallic cooling water tubing and hoses.

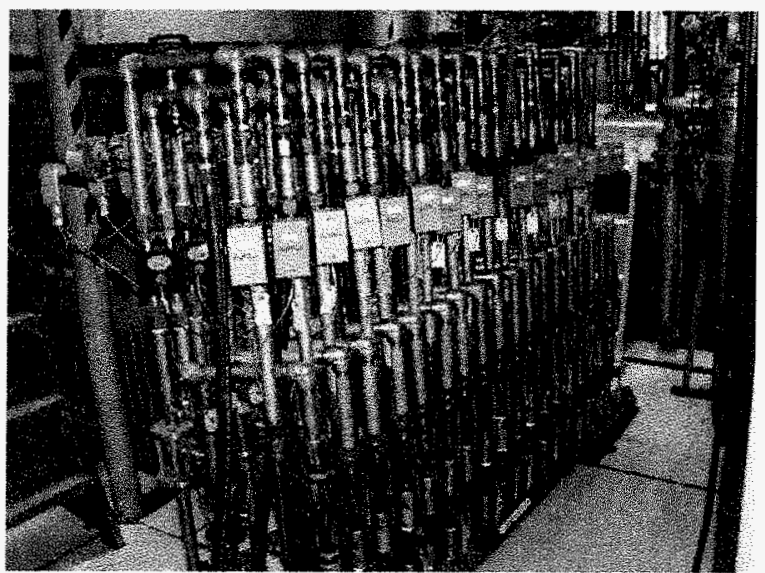

Fig. 6. Ion source cooling water supply and return manifolds and connecting hoses. 
Because DO levels are measured at a considerable distance downstream of the sources, significant localized oxidation and corrosion of the sources may result from higher than measured DO concentrations in the stagnant water at the NBIS. Data gathered during cyclic PLC operation of the cooling system showed a $3.5 \mathrm{ppb} / \mathrm{hr}$ average increase of system DO levels when the system water is not circulating (Fig. 7).

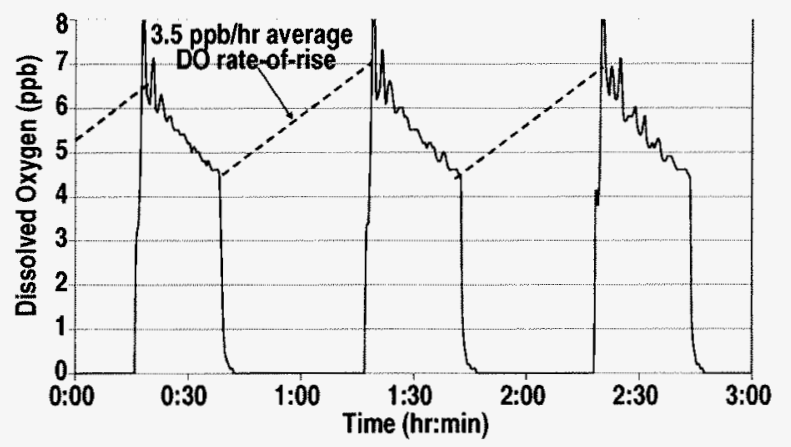

Fig. 7. DO levels during PLC cyclic operation of pump.

\section{OPERATIONS AND PERFORMANCE AFTER RECENT UPGRADE}

To decrease the likelihood of significant localized oxidation and corrosion of the NBIS, a new auxiliary circulation loop and pump was installed. A remotely actuated supply control valve and a remote actuator for an existing return isolation valve were also added (Fig. 8).

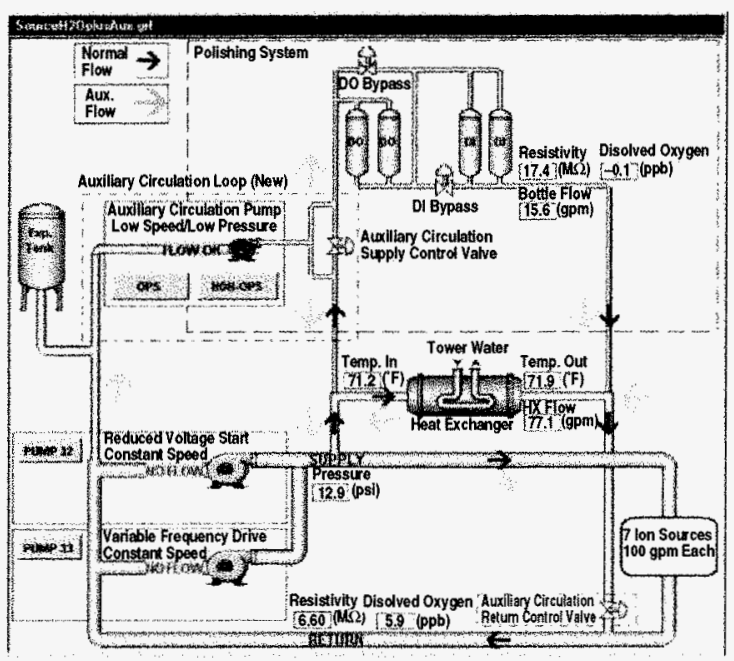

Fig. 8. NBIS cooling water system after addition of the auxiliary circulation pump loop. Light grey arrows show the flow path for the auxiliary pump.

This most recent upgrade is designed to enhance ongoing efforts to reduce DO levels and conserve electrical energy. When the neutral beams are not operating, a $3.73 \mathrm{~kW}(5 \mathrm{hp})$ pump runs continuously. The discharge of the pump is divided by closing the auxiliary circulation supply control valve. $57 \ell / \mathrm{m}(15 \mathrm{gpm})$ is directed through the de-ionizing/de- oxygenating bottles to the discharge side of the heat exchanger. Here, shutting the auxiliary circulation return control valve blocks the normal return path to the return header. This forces the effluent from the de-ionizing/deoxygenating bottles backwards through the heat exchanger where it joins the remaining output of the auxiliary circulation pump. This combined flow continues to travel backwards through what is normally the supply piping to the heat exchanger until it reaches the $8 "$ supply header. From there it resumes flowing in the normal direction through the ion sources in the DIII-D machine hall and back to the suction side of the pump via the return header. Continuous circulation of the system water eliminates the high-amplitude oscillating DO levels associated with the intermittent operation of the $74.6 \mathrm{~kW}(100 \mathrm{hp})$ pump. While the oscillatory startup DO levels cannot be completely eliminated, their amplitude is significantly lower and the damping of the oscillation is increased (Fig. 9).

Implementation of the auxiliary circulation loop significantly lowers the operating costs during non-beam operating times from $\$ 22,338$ to only $\$ 3,191$ per year based on electricity priced at $11 \% / \mathrm{kwh}$, and will have a payback time of less than ten months.

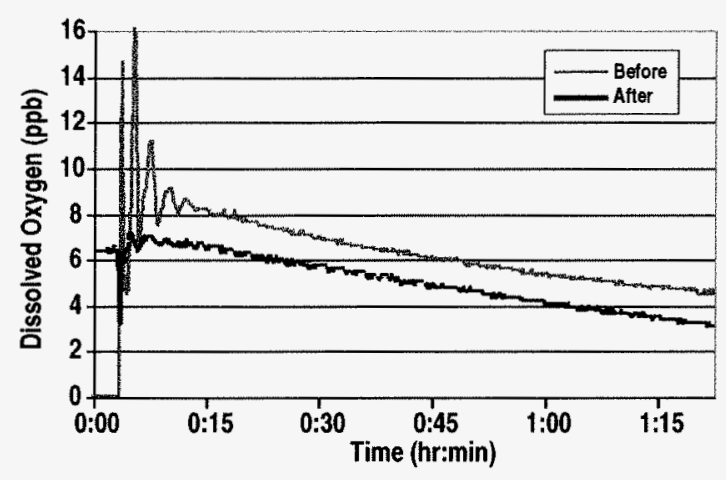

Fig. 9. Dampened DO oscillations at startup after recent auxiliary circulation upgrade.

\section{CONCLUSION}

Dissolved oxygen in the cooling water of NBIS has always been a concern. Isolation of the NBIS cooling water from other systems and implementation of higher resolution measurement and datalogging capability has greatly improved our awareness of the DO present in the cooling water. Improved operating procedures under PLC control and the addition for an auxiliary circulation pump have enabled us to continuously control and minimize the amount of DO present and consequently have significantly reduced the risk of corrosion and loss of material from the molybdenum components of the NBIS. The electrical energy conserved by these changes is substantial and the value of the expected increase in longevity of the irreplaceable NBIS is incalculable.

\section{ACKNOWLEDGMENT}

Work supported by the U.S. Department of Energy under Contract DE-AC03-99ER54463. 